\title{
Therapist characteristics and their effect on training outcomes: what counts?
}

Article

Accepted Version

Branson, A. and Shafran, R. (2015) Therapist characteristics and their effect on training outcomes: what counts?

Behavioural and Cognitive Psychotherapy, 43 (3). pp. 374-380. ISSN 1352-4658 doi:

https://doi.org/10.1017/S1352465814000642 Available at https://centaur.reading.ac.uk/39438/

It is advisable to refer to the publisher's version if you intend to cite from the work. See Guidance on citing.

Published version at: http://dx.doi.org/10.1017/ S1352465814000642

To link to this article DOI: http://dx.doi.org/10.1017/S1352465814000642

Publisher: Cambridge University Press

All outputs in CentAUR are protected by Intellectual Property Rights law, including copyright law. Copyright and IPR is retained by the creators or other copyright holders. Terms and conditions for use of this material are defined in the End User Agreement.

www.reading.ac.uk/centaur

\section{CentAUR}

Central Archive at the University of Reading 
Reading's research outputs online 
left running head: A. Branson and R. Shafran

Right running head: Therapist characteristics and training

\title{
Therapist Characteristics and their Effect on Training Outcomes: What Counts?
}

\author{
Amanda Branson and Roz Shafran
}

University of Reading, $U K$

Reprint requests to Amanda Branson, School of Psychology and CLS, University of Reading, Earley Gate, Reading, Berkshire RG14 6AL, UK. E-mail: a.branson@reading.ac.uk An extended version is also available online in the table of contents for this issue:

http://journals.cambridge.org/jid_BCP 
Background: Evidence exists for a relationship between individual characteristics and both job and training performance; however relationships may not be generalizable. Little is known about the impact of therapist characteristics on performance in postgraduate therapist training programmes. Aims: The aim of this study was to investigate associations between the grades of trainee Low-Intensity and High-Intensity cognitive behavioural therapists and individual characteristics. Method: Trainee Low-Intensity $(n=81)$ and High-Intensity $(n=59)$ therapists completed measures of personality and cognitive ability; demographic and course grade data for participants were collected. Results: Degree classification emerged as the only variable to be significantly associated with performance across assessments and courses. Higher undergraduate degree classifications were associated with superior academic and clinical performance. Agreeableness was the only dimension of personality to be associated (positively) with clinical skill. Age was weakly and negatively associated with performance. Conclusions: Relationships between individual characteristics and training outcomes are complex and may be context specific. These results could have important implications for the selection and development of therapists for Low or High-Intensity cognitive behavioural therapy (CBT) training.

Keywords: Training, outcome, cognitive behavioural therapy, IAPT. 


\section{Introduction}

An important yet often neglected area of investigation within the field of training and development has been the exploration of factors associated with training and academic performance. Whilst attention has been given to the role of the therapist on treatment outcomes, little is known about factors associated with performance in therapy training. Cognitive ability and academic attainment are consistently found to predict training and job performance (Richardson, Abraham and Bond, 2012), and personality may add meaningfully to the variance explained (Barrick and Mount, 1991). A few studies have explored the effect of demographic variables (e.g. age, gender, experience) on performance on postgraduate therapist training programmes; however, courses are not all cognitive behavioural in nature and results are mixed (Siqueland et al., 2000).

The Improving Access to Psychological Therapies (IAPT) initiative affords a valuable opportunity to investigate the influence of therapist characteristics on training outcomes. The English Government has made a commitment to train 6000 therapists to deliver evidencebased Low-Intensity interventions and CBT for depression and anxiety disorders. Within the IAPT framework, Low-Intensity interventions are provided by Psychological Wellbeing Practitioners (PWPs) and CBT is provided by High-Intensity therapists. Training is provided at a postgraduate level ${ }^{1}$ in partnership between National Health Service (NHS) IAPT Services and Universities, following national course curricula (www.iapt.nhs.uk).

The aim of this study was to investigate the impact of individual characteristics on the training outcomes of trainee PWPs and High-Intensity therapists. It was predicted that: 1)

\footnotetext{
${ }^{1}$ A graduate route is available for PWPs; however, all therapists in the current sample had studied an undergraduate degree.
} 
cognitive-ability and academic attainment (degree classification) would be positively associated with clinical and academic performance; 2) the personality dimensions of conscientiousness (positively), openness (positively) and neuroticism (negatively) would be associated to academic work and agreeableness (positively) to clinical work; 3) age and experience would be related (positively) to academic and clinical performance and that gender would be unrelated to either aspect of performance.

\section{Method}

\section{Sample}

Participants were trainees enrolled on the Postgraduate Certificate (PWP) and Diploma (High-Intensity) courses at Reading University between 2008 and 2012. Of the 239 trainees enrolled on these courses, $140(59 \%)$ consented to be involved $(n=81 ; 65 \%)$ and $n=59$ $(51 \%)^{2}$. Trainees were predominantly female $(78 \%$ and $73 \%)$, PWPs were younger $(M=29.5$, $S D=7.27$ vs. $M=37.7, S D=8.53)$ and had fewer years of experience $(M=1.84, S D=1.86$ vs. $M=9.49, S D=17.01)$ than High-Intensity therapists. Of those who consented to be involved, 114 trainees completed the measure of personality [NEO PI-R, $n=60(74.1 \%)$ and $n=52$ (88.1\%)] and 122 completed the measure of cognitive ability [Ravens Progressive Matrices, $n$ $=68(84 \%)$ and $n=54(91.5 \%)]$. No significant differences emerged across cohorts in terms of age, gender, years of experience or degree grade (see extended report).

\section{Assessments and measures}

Training (grades) and demographic data were collected from student records. Clinical and academic work is rated by experienced CBT therapists; in-house inter-rater reliability is

\footnotetext{
${ }^{2} \mathrm{PWP}$ feature first in parenthesis
} 
good, interclass correlations for High-Intensity and PWP clinical and academic assessments range from $.50-.84$.

\section{Clinical assessments}

Observed Standardised Clinical Examinations (OSCEs) were used to assess the competence of PWPs. Trainees undertook three OSCEs, which were rated using standardized scales detailed in the PWP curriculum (Reach Out; Richards and Whyte, 2009).

Cognitive Therapy Scale Revised (CTS-R; Blackburn et al., 2001) was used to assess High-Intensity clinical competence. Trainees submitted three audio-recordings of therapy sessions which were rated against 12 items on a 7 -point Likert scale $(0=$ incompetent to $6=$ expert). The threshold for competence on the CTS-R is 36 .

\section{Academic assessments}

Written assessments examine trainees' knowledge and understanding of clinical theory and practice. Three reflective-analyses of 1000 words (PWP and High-Intensity), three case reports of 2500 (High-Intensity), and four written examinations (PWP) were undertaken. Academic assessments were graded 0-100 using internal rating-scales; the pass mark was $50 \%$.

\section{Personality}

The Big-Five personality dimensions of neuroticism, extraversion, openness to experience, conscientiousness, and agreeableness were measured using the 240-item NEO-PI-R (Costa and McCrae, 2006).

\section{Cognitive ability}


Ravens Progressive Matrices were implemented. Ravens is a measure of non-verbal reasoning comprising five sets of 12 problems, resulting in a raw score between 0 and 60 (Raven, Raven and Court, 1998).

\section{Demographic variables}

Age (in years), gender, and years of relevant clinical experience (not specifically CBT) were collected from student records.

\section{Results}

\section{Descriptive statistics}

Distribution of assessment grades and mean NEO PI-R and Ravens scores, and comparison with published UK norms (Costa and McCrae, 2006) can be found in the extended version of this report.

\section{Associations between variables}

With alpha set at .01 to control for type 1 error, significant correlations were observed between all assessment types in PWP and High-Intensity trainees $\left(r_{s}=.5\right.$ to $.77, p<.001$ for all) suggesting overlap in the knowledge and skills under evaluation.

Patterns of association between therapist characteristics and performance were generally weak and inconsistent. Hypothesis 1 was partly supported: Ravens was unrelated to clinical or academic performance $\left(r_{s}=.031\right.$ to $\left.r_{s}=.256, p>.01\right)$. However, degree classification was significantly and positively associated with academic work in both groups $\left(r_{s}=-.201\right.$ to $r_{s}=-.457, p<.01$ for all $)$, and with clinical work in High-Intensity trainees $\left(r_{s}=\right.$ $-376, p<.01)$. Higher degree classifications were associated with higher assessment grades. Results did not support hypothesis 2 : agreeableness was the only dimension of personality to 
be significantly related to performance, but only with the PWP reflective-analyses $\left(r_{s}=.33, p\right.$ $=.01)$.

Limited support was also found for Hypothesis 3. Age was negatively associated with clinical and academic work across groups but associations only reached significance for the PWP exam $\left(r_{s}=-.35, p=.001\right)$, and High-Intensity reflective-analyses $\left(r_{s}=-.34, p=.009\right)$. Experience was not significantly associated with performance.

Significant Point-Bisarial correlations between gender and OSCE $\left(r_{p b}=.35, p=.001\right)$, reflective-analyses $\left(r_{p b}=-.29, p=.008\right)$ and exams $\left(r_{p b}=-.30, p=.008\right)$ indicated that female PWP therapists outperformed males, but this was not observed in High-Intensity therapists.

\section{Effect of prior academic attainment}

A series of 1-Way ANOVAs were conducted to further explore the relationship between degree classification and performance (see Figure 1). With alpha set at .05, ANOVA revealed a significant effect of degree classification on mean OSCE grade, $(F(2,75)=3.51$, MSE $=$ $66.3, p=.04)$; and CTS-R, $(F(2,56)=5.37, \operatorname{MSE}=54.5, p=.007)$.A similar pattern emerged for the PWP exam $(F(2,75)=10.12, \mathrm{MSE}=43.81, p<.00)$, and reflective-analyses, $(\mathrm{F}(2,75)$ $=6.93, \mathrm{MSE}=55.51 p=.002)$. Degree classification also significantly affected highintensity therapists' reflective-analysis grades $(\mathrm{H}(2)=12.29, p=.002)$. Results were less robust for the high-intensity case report; although data followed a similar pattern, ANOVA was non-significant, $(F(2,55)=1.80, \mathrm{MSE}=50.5, p=.17)$.

[INSERT FIGURE 1 HERE] 


\section{Discussion}

This study investigated relationships between therapist characteristics and performance on clinical and academic assessments in trainee Psychological-Wellbeing-Practitioners and High-Intensity CBT therapists. Results provided limited support for the majority of hypotheses.

A surprising finding was the weak association between cognitive-ability and all assessment types. As the range of intelligence narrows from primary to tertiary education, correlations between cognitive-ability and academic success decrease in magnitude (Chamorro-Premuzic and Furnham, 2005); this restriction of range may have attenuated the strength of observed associations.

Degree classification was the only variable associated with clinical (High-Intensity only) and academic assessments in PWP and High-Intensity training programmes. Trainees achieving higher classifications in their undergraduate degree do better clinically and academically than those with lower classifications. This finding mirrors the extensive body of research observing a positive relationship between academic attainment and subsequent training across educational spheres, and extends the limited literature focusing on postgraduate populations. The evidence to date suggests that the best predictor of academic and clinical performance is likely to be past academic performance.

Limited support was found for an association between training outcomes and therapist personality, and the pattern of association was inconsistent across assessments and training groups. This supports existing evidence for the lack of generalizability of personality measures across settings (Barrick and Mount, 1991). 
Older trainees performed less well than their younger counterparts, replicating previous findings (McManus, Westbrook, Vazquez-Montes, Fennell and Kennerley, 2010). One possible explanation for this finding is proactive interference; a phenomenon whereby previously acquired knowledge, skills and attitudes attenuate the acquisition of new information. A second explanation is role conflict; older trainees may be juggling multiple roles resulting in reduced quantity and/or quality of study time. Experience was unrelated to clinical or academic performance. It may therefore be the type of experience, rather than experience per se that is important in the prediction of performance.

Contrary to prediction, female trainees performed significantly better, both clinically and academically, than males, but this was true only for PWP trainees. As the association was not consistent across training groups this finding may reflect random variation in ability in male PWP trainees in the current sample. Future research should investigate the malefemale performance gap across other IAPT courses to see whether findings are replicated. A gender gap in performance has important implications for course developers and trainers in terms of establishing how to optimize training for both genders.

\section{Strengths, limitations and future lines of enquiry}

A strength of the current study is the range of therapist factors that were investigated and the inclusion of a large sample of trainees spanning three academic years on two different courses. Nevertheless, the uncontrolled retrospective nature of the study means that results cannot be conclusive. Since the study was conducted on a subset of PWP and high-intensity therapists trained at one university, the data may not be representative, and the possibility of this is highlighted through the presence of cohort effects in clinical performance and PWP examinations (see extended report). Before conclusions can be drawn, researchers will need 
to incorporate representative samples and afford greater attention to therapist characteristics in order to more fully understand how they impact upon training performance.

If future research confirms degree classification to be the most important correlate of training success, there are potentially important implications for the selection of candidates for postgraduate training. However, as degrees are not a requirement for PWPs, it may be that a broader perspective on past performance is more useful, including assessments such as appraisal scores as well as GCSE results. A potentially concerning finding was the negative association between age and performance. Correlational analyses provide confirmation of a relationship, but conclusions cannot be drawn on causal link. A qualitative approach may offer a richer, more comprehensive understanding of the barriers faced by older trainees, and will help course developers to provide adequate support to reduce the inequality of performance across the age range.

\section{Conclusions}

The current study extends the limited body of research focusing on the effect of individual characteristics on postgraduate performance. With the exception of degree classification, no variables were consistently associated with performance. If individual characteristics are to be used in the selection of therapists for postgraduate programmes a range of variables should be considered, particularly past performance. Furthermore, whilst experience is a prerequisite of entry onto the High-Intensity programme, this study indicates that it would be unwise for course developers to make assumptions that experience necessarily equates to excellence.

\section{Acknowledgements}


This study was supported by the 2010 Research Grant from the British Association for Behavioural and Cognitive Psychotherapies (BABCP).

\section{References}

Barrick, M. R. and Mount, M. K. (1991). The big five personality dimensions and job performance: a meta-analysis. Personnel Psychology, 44, 1-26.

Blackburn, I., James, I., Milne, D., Baker, C., Standart, S., Garland, A., et al. (2001). The Revised Cognitive Therapy Scale (CTS-R): psychometric properties. Behavoural and Cognitive Psychotherapy, 29, 431-446.

Chamorro-Premuzic, T. and Furnham, A. (2005). Personality and Intellectual Competence. New York: Lawrence Erlbaum.

Costa, P. T. and McCrae, R. R. (2006). NEO Revised: NEO Personality Inventory Manual (UK ed.). Oxford: Hogrefe.

McManus, F., Westbrook, D., Vazquez-Montes, M., Fennell, M. and Kennerley, H. (2010). An evaluation of the effectiveness of diploma-level training in cogntive behaviour therapy. Behaviour Research and Therapy, 48, 1123-1132.

Raven, J. C., Raven, J. and Court, J. H. (1998). Manual for Raven's Progressive Matrices and Vocabulary Scales. Section 3, The Standard Progressive Matrices. Oxford: Oxford University Press. 
Richards, D. A. and Whyte, M. (2009). Reach Out. National Programme Educator Materials to Support the Delivery of Training for Psychological Wellbeing Practitioners Delivering Low Intensity Interventions (2 ed.). London: Rethink.

Richardson, M., Abraham, C. and Bond, R. (2012). Psychological correlates of university students' academic performance: a systematic review and meta-analysis. Psychological Bulletin, 138, 353-387.

Siqueland, L., Crits-Christoph, P., Barber, J. P., Butler, S. F., Thase, M., Najavits, L., et al. (2000). The role of therapist characteristics in training effects in cognitive, supportive-expressive, and drug counseling therapies for cocaine dependence. The Journal of Psychotherapy Practice and Research, 9, 123-130. 


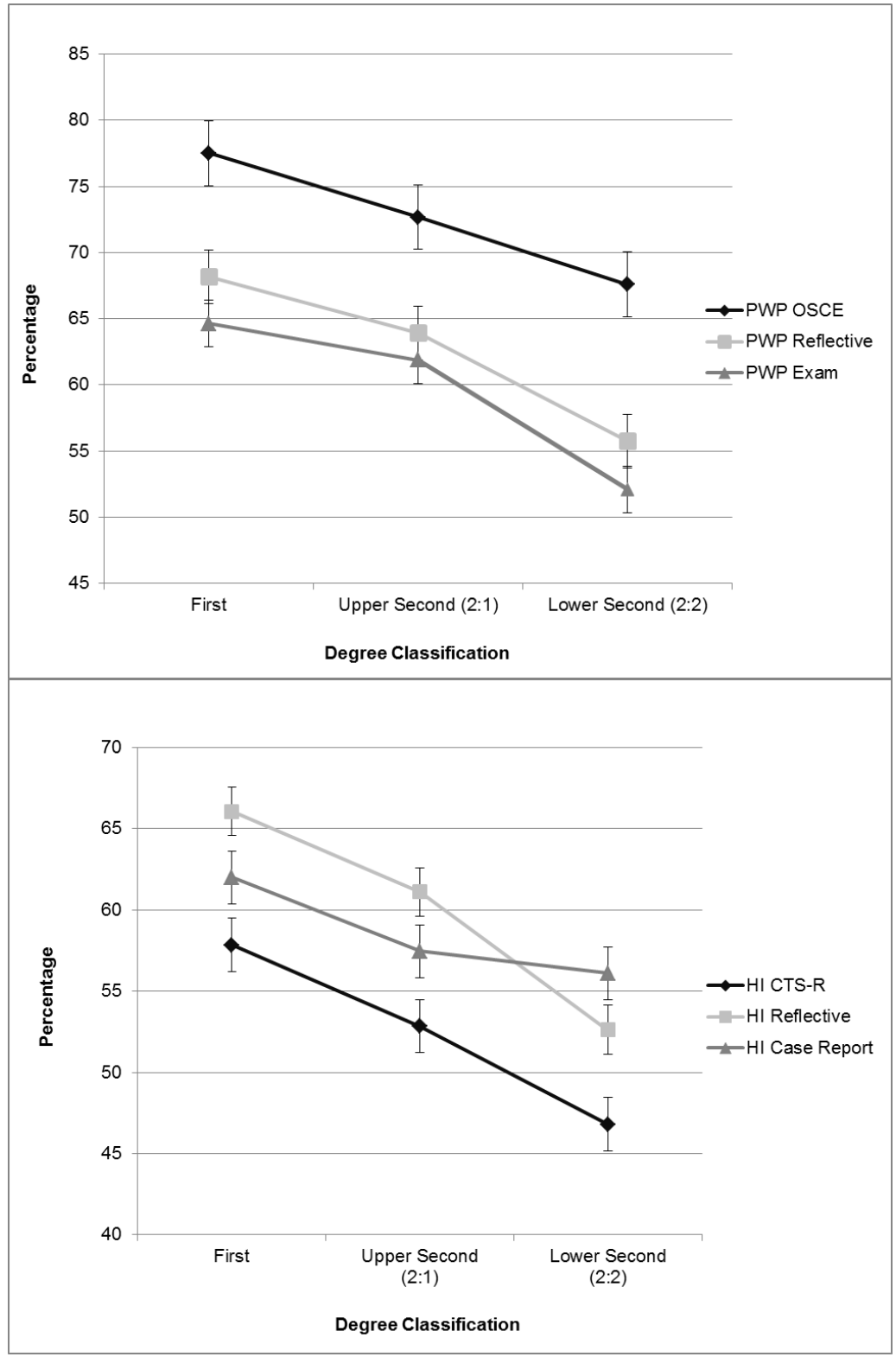

Figure 1. Mean assessment grades by degree classification for PWP and HighIntensity $(\mathrm{HI})$ therapists 